\title{
O PLANEJAMENTO DA EDUCAÇÃO BRASILEIRA (PNE 2001-2024)
}

\author{
LA PLANIFICACIÓN DE LA EDUCACIÓN BRASILEÑA (PNE 2001-2024)
}

THE BRAZILIAN EDUCATION PLANNING (PNE 2001-2024)

Paulo Gomes LIMA ${ }^{1}$

RESUMO: O propósito desse estudo é discutir as relações entre o planejado (metas e estratégias) à luz dos Planos Nacionais de Educação do Brasil (PNE 2001-2010; 2014-2024), as solicitações e necessidades da sociedade, tendo como eixo transversal a democratização do acesso e a universalização de educação para todos, a partir da agenda das políticas públicas para a educação. $\mathrm{O}$ estudo foi conduzido por uma abordagem qualitativa de cunho exploratório, utilizando como fontes alguns referenciais da literatura especializada (FRIGOTTO, 2007; DIAS SOBRINHO, 2012; TEIXEIRA, 2002; TURRA, ENRICONE; SANT'ANNA, 1995; DOURADO, 2011; LIMA, 2009, 2010, 2013) bem como base documental pertinentes aos dois Planos Nacionais de Educação do Brasil (BRASIL, 2001, 2014), além de dados do INEP Instituto Nacional de Estudos Pedagógicos Anísio Teixeira (2018) em datas que cobrem os balanços dos PNE's. Ao fim do estudo observou-se um descompasso entre metas previstas, metas alcançadas (ainda que parcialmente, no caso do segundo PNE ainda em vigência) e a não cobertura ou observância das solicitações demandadas pelos cidadãos brasileiros. Nas palavras de Dias Sobrinho (2012): "Uma sociedade que não consegue, ou não quer, estender os benefícios da escolarização de boa qualidade para todos, além de estar condenada ao empobrecimento crescente no sistema mundial de alta competitividade, é também uma sociedade perversa"; é necessário, portanto, outra lógica centrada na democratização e validação do direito social da educação sem contingências e desvios.

PALAVRAS-CHAVE: Educação brasileira. Políticas públicas de educação. Planos nacionais de educação (PNE's).

RESUMEN: El propósito de este estudio es discutir la relación entre lo planeado (metas y estrategias) a la luz de los Planes Nacionales de Educación de Brasil (PNE 2001-2010; 20142024), las demandas y necesidades de la sociedad, teniendo como eje transversal la democratización de acceso y universalización de la educación para todos, desde la agenda de políticas públicas para la educación. El estudio se realizó mediante un enfoque exploratorio cualitativo, utilizando como fuentes algunas referencias de la literatura especializada (FRIGOTTO, 2007; DIAS SOBRINHO, 2012; TEIXEIRA, 2002; TURRA, ENRICONE; SANT'ANNA, 1995; DOURADO, 2011; LIMA, 2009, 2010, 2013), así como la base documental pertinente a los dos Planes Nacionales de Educación de Brasil (BRASIL, 2001, 2014), y los datos del INEP - Instituto Nacional de Estudios Pedagógicos Anísio Teixeira (2018) sobre fechas que cubren los balances de los PNE. Al final del estudio, hubo un desajuste entre los objetivos esperados, los objetivos logrados (incluso parcialmente, en el caso del segundo PNE

${ }^{1}$ Universidade Federal de São Carlos (UFSCar), São Carlos - SP - Brasil. Professor permanente do programa de pós-graduação em Educação. Líder do Grupo de Estudos e Pesquisas Estado, Políticas, Planejamento, Avaliação e Gestão da Educação. ORCID: https://orcid.org/0000-0001-9932-4934. E-mail: paulolima@ufscar.br 
aún vigente) y la falta de cobertura o cumplimiento de las solicitudes exigidas por los ciudadanos brasileños. En palabras de Dias Sobrinho (2012): "Una sociedad que no puede o no quiere extender los beneficios de una educación de buena calidad a todos, además de estar condenada a un empobrecimiento creciente en el sistema mundial altamente competitivo, también es una sociedad perversa. "; Por lo tanto, se necesita otra lógica centrada en la democratización y validación del derecho social de la educación sin contingencias y desviaciones.

PALABRAS CLAVE: Educación brasileña. Políticas públicas de educación. Planes nacionales de educación (PNE's).

ABSTRACT: The purpose of this study is to discuss the relationship between the planned (goals and strategies), in the light of the National Education Plans of Brazil (PNE 2001-2010; 20142024), the demands and needs of society, having as its transversal axis the democratization of access and the universalization of education for all, from the agenda of public policies for education. The study was conducted by a qualitative exploratory approach, using as sources some references from the specialized literature (FRIGOTTO, 2007; DIAS SOBRINHO, 2012; TEIXEIRA, 2002; TURRA, ENRICONE; SANT'ANNA, 1995; DOURADO, 2011; LIMA, 2009, 2010, 2013), as well as the documentary base pertinent to the two National Education Plans of Brazil (BRASIL, 2001, 2014), as well as data from INEP - National Institute for Pedagogical Studies Anísio Teixeira (2018) on dates covering the balance sheets of the PNE's. At the end of the study, there was a mismatch between expected goals, goals achieved (even partially, in the case of the second PNE still in force) and the non-coverage or compliance of requests demanded by Brazilian citizens. In the words of Dias Sobrinho (2012): "A society that cannot or does not want to extend the benefits of good quality education to all, in addition to being condemned to growing impoverishment in the highly competitive world system, is also a perverse society"; therefore, another logic focused on the democratization and validation of the social right of education without contingencies and deviations is needed.

KEYWORDS: Brazilian education. Public policies of education. National education plans (PNE's).

\section{Introdução}

Sabe-se que as "politics" são fundamentais para a composição de um planejamento de políticas públicas, sem no entanto, se confundir com os seu processual de desenvolvimento, ou seja, enquanto nível de discussão nas distintas arenas, as politics antecedem as "public policies", caracterizando-se como espaço de poder onde distintos interesses e valores estão em recorrência, nesse sentido, o discurso com maior apoio e influências na perspectiva dos demais atores, constitui-se, de forma negociada, pauta para uma possível agenda ou encaminhamento de negociações. As policies, por sua vez, podem ser caracterizadas como as atividades desenvolvidas pelo governo de um país ou de instâncias subnacionais no planejamento e desenvolvimento de suas agendas que constituem as políticas públicas ou "public policies". 
As políticas públicas correspondem, portanto, aos valores e decisões priorizadas pelo governo, considerando o âmbito do processo da política. O seu desenvolvimento dar-se-á por meio do ciclo de políticas caracterizado pela a) formação de uma agenda (decisões sobre quais algumas pautas terão prioridade e que, constituem-se efetivamente em problemas políticos e não um "estado de coisas"), b) formulação da política/seu texto (elaboração das diretrizes, fundamentos, finalidades, definição de instrumentos e alternativas para o processo posterior da política pública), c) implementação (âmbito em que a política é colocada em prática, conforme a sua finalidade, ou seja, trata-se de uma intervenção na realidade que foi caracterizada como problema político e que através de ações concretas é trabalhada) e d) a avaliação da política (se atingiu ou não a finalidade a qual se destinava, se o seu desenho conseguiu reunir métricas centradas na eficiência, eficácia e efetividade). As políticas públicas devem ser planejadas conforme o setor, suas demandas e prioridades eleitas. A educação, por exemplo, se encaixa nas políticas públicas de corte social. O planejamento educacional, por meio das políticas públicas, conforme Turra, Enricone e Sant'Anna (1995, p. 16) tem como pressupostos básicos: a) o delineamento da educação no país, evidenciando o valor da pessoa e da escola na sociedade e b) a aplicação da análise - sistemática e racional - ao processo e desenvolvimento da educação, buscando torná-lo mais eficiente e passível de responder com maior precisão às necessidades e objetivos da sociedade.

O planejamento das políticas públicas no Brasil, no entanto, desde os anos de 1930 tem sido desenvolvido por meio dos interesses econômicos hegemônicos locais e articulados aos globais, considerando-se o processo do desenvolvimento industrial/comercial como eixos centrais e as políticas sociais como instrumentos de contrapartida, quando necessário aos acordos bi ou multilaterais. Ora, considerando-se a fala de Turra, Enricone e Sant'Anna (1995) acima observa-se que a lógica na realidade brasileira está invertida, inclusive para os tempos contemporâneos, mas não somente na realidade brasileira, visto que a mesma lógica incide sobre os países capitalistas avançados ou economicamente dependentes ou ainda com economias instáveis. É claro que a diferença está no grau de prioridade e inversão de recursos para o desenvolvimento de um planejamento que efetive as mudanças que se desejam. No entanto, quando entendemos que a lógica do capitalismo pode influenciar as direções das políticas públicas da educação dos países em desenvolvimento ${ }^{2}$, não é tão simples dizer que

${ }^{2}$ Como observamos em Lima (2009) A orientação da divisão internacional do trabalho pela imposição e determinação do imaginário social, estabelece os papéis definidos entre países desenvolvidos e em desenvolvimento mediante uma racionalidade instrumental que convoca à responsabilização solidária: empenho e inserção de políticas inclusivas, erradicação da pobreza e, para isso, forte ênfase na educação, centrada nos mesmos 
isso acontece em todos os lugares e tempos com a mesma força e intencionalidade, ou seja, o que marca fortemente sua expressão é o movimento da divisão internacional do trabalho e das determinações do mercado, tendo como veículos as agências multilaterais de financiamento e assistencialismo, acontece o delineamento da nova tipologia de "homem necessário" e que deveria ser formado pela internalização de seus ideários (LIMA, 2009).

O desenho do planejamento educacional do Brasil, atravessando o plano das políticas e das políticas públicas em particular, está imerso na lógica acima exposta, mais proximamente exemplificado pelos Planos Nacionais de Educação (2001-2010; 2014-2024), objeto de estudo desse trabalho, onde se desenvolveram agendas, metas e estratégias para a oferta, condições de permanência, expansão e sucesso escolar, sem no entanto, se observar as condições concretas para a sua efetivação, os enfrentamentos recorrentes nas arenas políticas e a necessidade de intercorrência com os cidadãos, visto ser a gestão democrática, um princípio transversal que todos os policy makers brasileiros, educadores e comunidade deveria observar.

\section{Plano nacional de educação (2001-2010): balanço e discussões}

Não foram poucas as políticas públicas para a educação elaboradas para a realidade brasileira entre a última década do século XX e a primeira do século XXI, mediante a orientação democrática enfatizada pela Constituição Federal de 1988 (BRASIL, 1988) que culminou na nova Lei de Diretrizes e Bases da Educação Nacional (LDBEN) No 9394/1996 (Brasil, 1996), e no desdobramento de emendas constitucionais que trataram da ampliação da escolaridade no Brasil (N. ${ }^{0}$ 53/2006 e 59/2009), seguidas da determinação constitucional quanto à elaboração de Planos Nacionais de Educação que garantiriam a continuidade de políticas regulatórias orientadas para o asseguramento de grande metas e estratégias em relação à qualidade de educação, à cobertura de oferta e ampliação do direito para toda a educação básica brasileira.

Entretanto, o balanço resultante do conjunto de políticas educacionais não se mostrou suficientemente satisfatório a partir do primeiro Plano Nacional de Educação (I PNE) previsto para o período de 2001 a 2010 mostrando que, se por um lado houve a quase universalização do ensino fundamental de nove anos no final da primeira década do século XXI, por outro lado, somente cerca de um terço de 29 milhões de pessoas foi atingido pela Educação de Jovens e Adultos, de um total de 50\% esperados pelo Plano; a repetência, o abandono e a erradicação do analfabetismo não foram satisfatoriamente trabalhados em nível de investimentos e ações

indicadores do mercado: eficiência, eficácia e produtividade, objetos muitas vezes intangíveis à lógica do atendimento universalizado das políticas sociais universalizadoras. 
concretas, ao ponto de não haver mudanças substanciais em sua diminuição percentual, visto o acentuado histórico de desigualdade social no Brasil. (LIMA, 2013). A figura 1, a seguir, explicitava tal realidade e trazia ao debate uma questão central: o que deu errado? Por que entre o planejado e o alcançado há um enorme fosso, visto não serem atingidas as metas desenhadas para o período? E nesse contexto, quais foram as prioridades do Estado brasileiro, que poderiam explicar tal descompasso? Tais questões serão contempladas ao longo desse trabalho.

Figura 1 - PNE (2001-2010): o projetado e o alcançado - Ensino fundamental e EJA

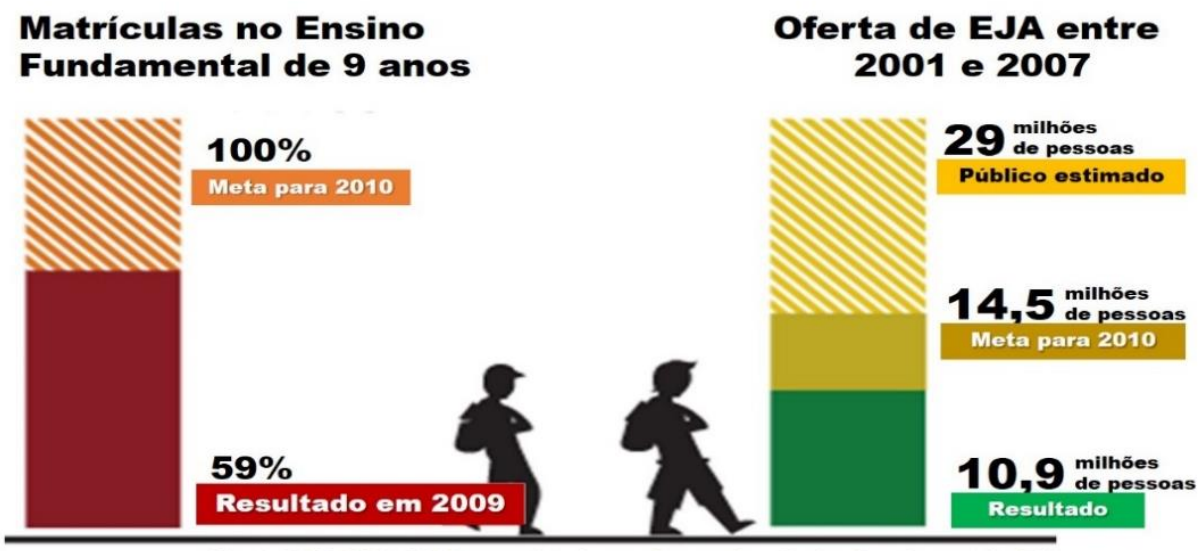

Fonte: Censo Escolar/MEC/INEP (2010) In: Moço (2010).

A educação infantil que deveria atingir $50 \%$ das crianças brasileiras em idade de creche no período previsto pelo PNE atingira somente $17,1 \%$ e a educação pré-escolar que tinha meta de $80 \%$ ficou abaixo do esperado, isto é, $77,6 \%$, como pode ser acompanhado na Figura 2:

Figura 2 - Acesso à educação infantil

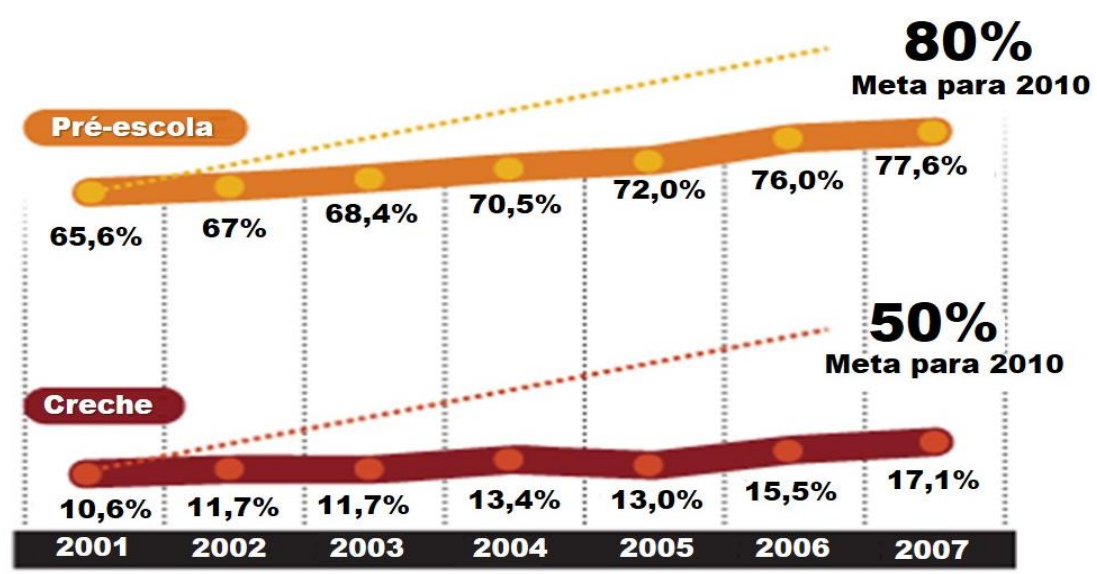

Fonte: Relatório O Direito de Apender (Unicef, 2009) In: Moço (2010).

O Instituto Paulo Montenegro e Ação Educativa (2012) registraram que não houve crescimento da taxa de pessoas consideradas plenamente alfabetizadas no Brasil, ou seja, se por 
um lado, $12 \%$ foi o índice que representou a queda dos analfabetos funcionais (analfabetismo e alfabetismo rudimentar), por outro lado, $13 \%$ foi o índice que registrou o aumento no percentual de pessoas pertencentes ao nível de alfabetismo básico 3 .

A preocupação com a economia nacional e a lógica neodesenvolvimentista ${ }^{4}$ da primeira década do século XXI, entre o atendimento aos apelos do mercado e as políticas de proteção social certamente foram fatores determinantes para não se alcançar as metas previstas para a educação. Aqui não serão tratadas todas as modalidades e níveis da educação brasileira, visto o recorte do trabalho, vale dizer no entanto, que em nível do I PNE, o anúncio sobre o planejado fora muito preconizado como caminho para reverter a trajetória histórica de índices negativos e alarmantes da educação nacional, no entanto, a denúncia do jogo político é uma outra face que se sobrepõe, atestando que outras prioridades tomaram espaço. Logo, a sistemática de um projeto com maior clareza, com dados mais realistas não fora contemplado, ainda que, em meio ao processo do primeiro PNE, por conta de um Plano de Contingência do governo de Luís Inácio Lula da Silva (Plano de Desenvolvimento da Educação), medidas de políticas sociais tivesse tentado minorar o quadro (por meio de decretos da Presidência), tal esforço seria somente atenuado, fechando-se a década com números aquém de uma transformação educacional ao menos próxima ao desejável ${ }^{5}$.

O Programa de Aceleração do Crescimento (PAC) apresentado pelo governo Lula à sociedade brasileira, passou a vigorar a partir de 28 de janeiro de 2007. O PDE como uma fração do PAC fora caracterizado pelo próprio presidente Lula como "Uma revolução na educação brasileira" e que a seu ver, deveria responder a lacunas históricas até então não contempladas de forma parcial ou em sua totalidade. Esse primeiro delineamento previa a articulação da sociedade civil e os entes federados para, estrategicamente, promover a oferta de educação para todos e de qualidade. Isso se faria mediante parcerias e controle dos índices registrados quanto ao aproveitamento discente (IDEB) e a verificação sazonal por avaliações externas, como

${ }^{3}$ No site do governo brasileiro é expresso que a taxa de analfabetismo caiu de 13,63\% em 2000 para 9,6\% em 2010, conforme dados do IBGE.

${ }^{4}$ Para Sampaio Jr. (2012, p. 683) o "[...] neodesenvolvimentismo só pode fantasiar sobre a possibilidade de um desenvolvimento capitalista nacional porque ignora os encadeamentos necessários entre concentração e centralização dos capitais, dominância absoluta do capital financeiro sobre o processo de acumulação, lógica de império que preside a ação das potências imperialistas (Estados Unidos à frente), total subordinação da ordem econômica mundial aos imperativos do capital financeiro, incontrolabilidade do capital, crise terminal do keynesianismo e tendência à reversão neocolonial nos países que fazem parte da periferia da economia mundial." ${ }^{5}$ Saviani (2009) advertiu que o PNE(2001-2010) previa no artigo $3^{\circ}$ que avaliações periódicas do alcance de suas ações deveriam ser realizadas, assim no quarto ano de vigência que se situaria em 2004 isto deveria acontecer, afim de se corrigirem as deficiências e distorções, mas de fato o dispositivo legal não foi observado. Somente quando estava a menos de quatro anos para ser finalizado o período de duração do referido PNE foi anunciado o PDE. Diga-se de passagem, essa organização desse plano via decretos, contou com a substancial participação da iniciativa privada. 
exemplo, SAEB, Prova Brasil, ENEM. Quanto à educação superior, as palavras expansão e democratização seriam os norteadores no contexto das razões do PDE, considerando os seguintes princípios: a) expansão da oferta de vagas, b) garantia de qualidade; c) promoção de inclusão social pela educação; d) ordenação territorial e e) desenvolvimento econômico e social (BRASIL, 2012).

Sem dúvida alguma o estabelecimento de políticas para o desenvolvimento da democratização da educação num país é urgente e decisivo para romper com a educação de elite historicamente enraizada, no entanto, o PDE, como uma interface das políticas educacionais, segundo Saviani (2009) pode ser caracterizado muito mais como um "programa de metas" do que um plano propriamente dito, dadas as tentativas pontualizadas para se alcançar algumas metas em determinado tempo (2017), visando a duplicação de vagas no ensino superior, ficando aquém da proposta do PNE (2001-2010) que, pelo menos previa um número total de vagas para $30 \%$ dos jovens entre 18 e 24 anos (e mesmo assim não alcançou o alvo para a década), portanto, um alvo que em tese deveria ser tangível. Para atingir as metas do PDE três instrumentos foram considerados como determinantes: a) Reestruturação e expansão das universidades: Programa de Apoio a Planos de Reestruturação e Expansão das Universidades Federais (REUNI) e Plano Nacional de Assistência Estudantil (PNAES); b) Democratização do acesso: Programa Universidade para Todos (PROUNI), reformulação do Fundo de Financiamento ao Estudante do Ensino Superior (FIES) e c) Avaliação e regulação: Sistema Nacional de Avaliação da Educação Superior (SINAES) via Exame Nacional do Desempenho dos Estudantes (ENADE).

Embora o desenvolvimento do Plano Nacional de Educação (2001-2010) estivesse em desenvolvimento, como se explicaria a elaboração do PDE e seu estabelecimento de ações via decretos governamentais, considerando a observação de Saviani, quanto a ser este antes um "programa de metas" do que um plano de educação? Por que ocorreu a proposição naquele momento histórico e não quando da conclusão do PNE que estava em curso, quando aí sim, se justificaria a construção do próximo PNE (2011-2020)?

Ramos (2007) observa que na elaboração e processo de implementação do PDE não houve uma participação direta com muitos movimentos representativos, dentre os quais, a Confederação Nacional dos Trabalhadores em Educação (CNTE), a União Nacional dos Conselhos Municipais de Educação (UNCME), a União Nacional dos Estudantes (UNE), a União Brasileira dos Estudantes Secundaristas (UBES) e a Associação Nacional Pela Formação de Professores (ANFOPE). O âmbito que poderia ser compreendido como avanço no conjunto do PDE quanto à educação básica foi a instituição do IDEB, o "Provinha Brasil" e o Piso Salarial do Magistério. Os dois primeiros por considerarem a relação do rendimento do aluno 
com os fluxos de evasão, repetência e esforços para os aspectos qualitativos e o terceiro, como meta que prometia "melhorar" o investimento na dignidade do professor pelo reconhecimento de seu papel social. De inclinação neodesenvolvimentista, o governo de então assume continua a conferir ao Estado a dimensão de "Estado Avaliador", como no governo anterior, mas agora com métricas mais próximas ao mercado internacional ${ }^{6}$, ainda que em discurso interno, a intencionalidade anunciada fosse outra. $\mathrm{O}$ discurso e ações economicistas e a ênfase sobre o pedagógico como resolutor que questões estruturais inviabilizaram um olhar e planejamentos mais acurados para se atingir até mesmo as metas do PDE e ainda, ficando ainda mais distante do PNE de então.

Ora, se há a defesa de democratização da educação e sua proporcional expansão em todos os níveis, haveria que se buscar a instituição de fóruns representativos em que todas as vozes pudessem expressar a sua contribuição social e inferências que orientariam as conquistas sociais, entretanto, o PDE se constituiria como instrumento fragmentário e fragmentado das correções que se desejava e o pior, não havia precisão e previsão de investimentos específicos do PIB em educação frente aos desafios que se faziam naquele momento. Havia o reconhecimento de que se pensar num percentual para a educação via PIB era necessário, mas nada que ultrapassasse a casa dos $5 \%$ naquele momento. Não, somente a boa vontade, como aponta Saviani (2009), seria suficiente para se alcançar a educação de qualidade que a sociedade brasileira necessitava, uma vez que os recursos financeiros significativos para dar condução ao PDE, distintos dos 3,5\% do PIB que até aquele momento era aplicado não dariam conta de cobertura da educação como um todo. Se falava sobre a projeção de 5\% em 2007, o que Saviani destacava era que desde 1997 ele chamara a atenção para o percentual de 8\% como necessário.

Por fim, os objetivos centrais expressos pelo PNE (2001-2010), não atingiram as metas previstas na conjuntura de um novo governo que se instalara. Tais objetivos eram centrados em 4 eixos: a) a elevação global do nível de escolaridade da população; b) a melhoria da qualidade do ensino em todos os níveis; c) a redução das desigualdades sociais e regionais no tocante ao acesso e à permanência, com sucesso, na educação pública e d) democratização da gestão do ensino público, nos estabelecimentos oficiais, obedecendo aos princípios da participação dos

${ }^{6}$ É oportuno a discussão de Almeida, Schneider e Vazquez (2016, p. 11) ao afirmarem que o Estado-Avaliador "[...] constitui um dos mais expressivos dispositivos disseminados em larga escala pelos organismos internacionais como parte importante das novas formas de regulação pelas quais deve operar a reforma gerencial dos Estados Nacionais. Por meio da implantação de sistemas de indicadores nacionais e internacionais de responsabilização e prestação de contas (accountability), desenvolvidos em perspectiva comparada, o Estado-avaliador passa a controlar a gestão dos sistemas de ensino, o funcionamento das escolas e o trabalho dos professores orientando o delineamento e certas prioridades e certos padrões de qualidade." 
profissionais da educação na elaboração do projeto pedagógico da escola e a participação das comunidades escolar e local em conselhos escolares ou equivalentes (BRASIL, 2001).

O nível de escolaridade embora tenha tido relativo crescimento quantitativo, não fora atingido pelo correspondente nível de proficiência dos alunos no período. A qualidade da educação brasileira não avançou quanto ao nível de proficiência na língua portuguesa e matemática e as desigualdades sociais e regionais continuaram as mesmas, entretanto, o nível de pobreza absoluta foi diminuído de forma a mascarar o descompasso com a realidade socioeconômica da população aumentando os rincões da pobreza relativa. E, finalmente, embora houvesse maior espaço para se pensar a gestão democrática por meio de canais previstos na Lei de Diretrizes e Bases da Educação Nacional (Brasil, 1996), sendo o Projeto Político Pedagógico um deles; falhou-se em se estabelecer um trabalho de base para a escola se pensar, para entender que deveria delinear as metas no e pelo coletivo, nesse caso, a escola brasileira, regida pelo princípio de um Estado Democrático de Direito, predominantemente é autocrática com espaços relativos de participação social.

Há que se avançar na ampliação, discussão e encaminhamentos nessa diretriz. Todas as iniciativas encaminhadas para a melhoria da qualidade da educação no Brasil em qualquer nível de proposição devem ser mediadas pela indagação de sua validade frente à realidade social, econômica e política do país; sobre a direção que se pretende dar à escola e o grau de anuência ou não dos atores sociais em tal leitura; sobre a comunicação entre a escola, as redes de ensino de ensino e as solicitações da sala de aula, tendo em vista a diversidade socioeconômica que em meio ao discurso da democratização e qualidade educacional ainda admite uma escola dualista (LIMA, 2010).

\section{Plano nacional de educação (2014-2024): perspectivas e discussões}

Tendo o I PNE (2001-2010) não atingido as metas previstas e criticado tenazmente pelo governo de Lula e Dilma Rousseff, visto sua estrutura estar centrada no tripé "diagnósticodiretrizes-metas". No ano de 2010, ocorre a convocação de inúmeros representantes da sociedade dentre palestrantes, mídia, imprensa, equipe de coordenação, apoio e cultura para a Conferência, com o título "CONAE 2010 - construindo o Sistema Nacional Articulado de Educação: o Plano Nacional de Educação, diretrizes e estratégias de ação”. Dessa Conferência resultou um documento de 168 páginas com a planificação do PNE (2011-2020) e a previsão de desenvolvimento de um Fórum Nacional de Educação para discutir e encaminhar as grandes temáticas educacionais no Brasil. Em dezembro de 2010, a Presidenta Dilma Rousseff 
encaminhou o Projeto de Lei que aprovava o Plano Nacional de Educação para o período de 2011-2020, tendo como modificação, dentre outros a proposição de que o II PNE deveria ser mais enxuto e objetivo, com a definição de 20 metas e de estratégias que correspondessem o alcance das mesmas.

Entretanto, não fora aprovado de imediato, visto estarem ausentes elementos relevantes na construção de um planejamento nacional, precisamente a não reportação ao "diagnóstico" da realidade educacional brasileira. O que levou alguns parlamentares e segmentos da sociedade a iniciarem debates, discussões, encaminhamentos e novas solicitações quanto ao escopo da educação desejada para o Brasil. Feitos os levantamentos sobre o "diagnóstico" da realidade brasileira, a tramitação do projeto que recebeu o n. 8.035/2010 teve continuidade.

Somente quatro anos depois, por meio da Lei $N^{\circ} 13.005$, de 25 de junho de 2014, o II Plano Nacional de Educação (2014-2024) ${ }^{7}$, foi aprovado sem vetos, composto por 20 metas e 254 estratégias, trazendo como proposição pela primeira vez a previsão de investimento de $10 \%$ do Produto Interno Bruto (PIB) na educação, até o final da década. A métrica para mensurar os resultados do alcance das metas do PNE deveria estar ao encargo do INEP (Instituto Nacional de Estudos e Pesquisas Educacionais Anísio Teixeira) em cujo art. $5^{\circ}$ da Lei do II PNE, a cada dois anos, durante o decênio do PNE, seriam publicados estudos para aferição sobre a evolução do cumprimento das metas estabelecidas. (Brasil, 2014, p. 1).

Além da previsão oficial do acompanhamento das metas do PNE, o Movimento Todos pela Educação ${ }^{8}$, disponibiliza uma ferramenta de controle social denominada de "Observatório do PNE”, prevendo o acesso à informação sobre o status das metas do PNE, a qualquer tempo e servindo de indicadores para todos os entes federados e gestores. Ainda que o II PNE tenha se constituído de maneira mais democrática que o primeiro (DOURADO, 2011), ao se observar as 20 metas estabelecidas, nota-se um descompasso entre a previsão e o seu alcance, por exemplo (ver meta 1), ainda que $91,7 \%$ das crianças de 4 e 5 anos estejam matriculadas na préescola, para a faixa etária de 0 a 3 anos o percentual é de 32,7\%, tomando o ano de 2017 como referência, portanto, ao final da década o alcance para essa faixa etária não será atingido.

\footnotetext{
${ }^{7}$ Destaca-se que os objetivos do II PNE, assim como o I, afina-se com as diretrizes estabelecidas por organizações e eventos multilaterais, das quais o Brasil é signatário, como por exemplo a Conferência Mundial de Educação para Todos (1990), compromissos educacionais no Fórum Mundial de Educação para Todos (2000): o Compromisso de Dakar, objetivos assumidos no encontro Objetivos de Desenvolvimento do Milênio (ODM) da Organização das Nações Unidas (ONU), em 2000.

8 Apoiado pelo Banco Interamericano de Desenvolvimento (BID), esse movimento é composto por 24 organizações: Associação de Jornalistas de Educação - Jeduca, Associação Nova Escola, Capes, Cenpec, Comunidade Educativa Cedac, Fundação Itaú Social, Fundação Lemann, Fundação Maria Cecilia Souto Vidigal, Fundação Roberto Marinho/Canal Futura, Fundação Santillana, Fundação Telefônica Vivo, Fundação Victor Civita, Instituto Avisa Lá, Instituto Ayrton Senna, Instituto Natura, Instituto Paulo Montenegro, Instituto Rodrigo Mendes, Instituto Unibanco, Ipea, Mais Diferenças, SBPC, Todos Pela Educação, UNESCO e UNICEF.
} 
A porcentagem prevista de jovens de 15 a 17 anos na escola (meta 3 - 100\% até 2016), ainda não foi atingida, hoje registra-se cerca de $84,3 \%$ e quando se projeta para 2024 uma meta de $85 \%$ para jovens de 15 a 17 anos no ensino médio, nota-se que se está muito distante, visto que atualmente registra-se $62,7 \%$.

Tomando-se a meta 5 para efeitos de observação, vê-se que o seu alcance para o decênio está muito comprometido, visto que a aprendizagem adequada em leitura beira os $45,3 \%$ de $100 \%$ esperados; em relação à escrita são 66\% de 100\% e a aprendizagem adequada em matemática é de 45,5\%. Em relação à meta 7 , tanto no ensino fundamental do $6^{\circ}$ ao $9^{\circ}$ ano, quanto no Ensino Médio as porcentagens estão abaixo do previsto.

A elevação da taxa de escolaridade no Brasil ainda precisa de maiores cuidados, visto que se prevê que os brasileiros alcancem 12 anos de estudos, mas em 2017 se obteve o índice aproximado de 9,1 anos. Nota-se que simplesmente o registro da quantidade de anos não necessariamente pode representar o grau de aproveitamento ou proficiência desses estudantes.

Concernente a meta 15, conforme dados recentes do INEP (Brasil, 2018) cerca de 55,6\% tem formação adequada em sua área de formação, o que requererá concentrado em esforço na qualidade e quantidade de pessoas altamente qualificadas para trabalharem nas escolas de Educação Básica.

O que tudo isso nos indica? Certamente que o planejamento deve ser acompanhado de ações concretas e amplo debate com a população e seus representantes. Não basta planejar, não basta criticar os planos de governos anteriores se a história que se faz, não avança, não compreende as solicitações da população e ainda, se privilegia as intencionalidades dos governos e não do Estado. Especificamente ao olhar para o II PNE, o delineamento do plano percorreu instâncias consistentes de dimensão democrática, mas faltou e inda está faltando condições e articulaçõos suficientes para se efetivar ações concretas e suficiente governabilidade para o estabelecimento da educação desejada.

Dias Sobrinho (2012) observa que uma educação democrática e universalizada requer muito mais do que reconhecimento do direito ao direito, ou seja, reúne quantidade e qualidade como extensão material para todos. A ideia de povo como unidade, requererá também a modificação das orientações dos discursos políticos para educação, ao ponto de ao invés de se falar em educação inclusiva, se vivencie a educação não excludente, ao invés de se destacar a porcentagem de vagas para determinada fração social, haja a oferta como direito e conquista para todos. 


\section{Considerações finais}

Sabe-se que a necessidade de se pensar a educação em sua totalidade quer num percurso formativo via educação básica ou em universidades e cursos de educação superior tradicionais, quer em nível técnico e tecnológico não é algo novo, se sabe e se faz muito bem essa discussão em âmbito nacional, o que não se deve num país que se pronuncia democrático é condicionar a oferta de cursos à indução de uma amostragem da classe trabalhadora com o discurso de atendimento em suficiência às solicitações sociais, a isto Frigotto (2007) chamou de políticas focais. Com isso se mantem a desigualdade como produto e condição do projeto dominante da sociedade brasileira e as mudanças estruturais necessárias são colocadas à margem de quaisquer discussões e a culpabilidade da não inserção no quadro das oportunidades sociais recai sobre a responsabilização da criança, do jovem e adultos que não buscaram o seu lugar ao sol.

O que ocorre é que, no Brasil, quanto à sua natureza as políticas públicas podem ser caracterizadas como conjunturais ou emergenciais (objetivam amainar uma situação temporária, imediata), quanto a abrangência dos possíveis benefícios são segmentais (voltadas para um segmento da população, caracterizado por um fator determinado (idade, condição física, gênero etc.) e fragmentadas (destinadas a grupos sociais dentro de cada segmento), quanto aos impactos que podem causar aos beneficiários, ou ao seu papel nas relações sociais são mais distributivas (visam distribuir benefícios individuais; costumam ser instrumentalizadas pelo clientelismo do que redistributivas (visam redistribuir recursos entre os grupos sociais: buscando certa equidade, retiram recursos de um grupo para beneficiar outros, o que provoca conflitos) e ainda são regulatórias, isto é, visam definir regras e procedimentos que regulem comportamento dos atores para atender interesses gerais da sociedade; não visariam benefícios imediatos para qualquer grupo (TEIXEIRA, 2002).

Para que as políticas públicas de educação pudessem de fato corresponder as solicitações por universalização e democratização deveriam ser, quanto a sua natureza ou grau de intervenção, estruturais, possibilitando condições igualitárias das oportunidades sociais disponíveis para todos os estudantes, ao mesmo tempo que universais e regulatórias, garantindo-se a educação como prioridade, portanto, não excludente em sua finalidade. Ora, na organização social que tem o capital como sustentação isso dificilmente ocorrerá, daí ser o mais comum manter-se a estrutura sistêmica e favorecer a inclusão percentualizada como plataforma de atendimento representativo. O que por si, não modifica em nada a hegemonia do capital. É a luta pela ampliação dos espaços que poderá favorecer algumas conquistas na educação brasileira a partir da realidade que temos. É óbvio que boas intenções não são suficientes se o 
grau de políticas de proteção social não for observado, visto as desigualdades sociais em grande escala no panorama brasileiro.

\section{REFERÊNCIAS}

ALMEIDA, Maria de Lourdes Pinto de; SCHNEIDER, Marilda Pasqual; VAZQUEZ, Jaime Moreles. In: ALMEIDA, Maria de Lourdes Pinto de. et al (orgs.). Estado, políticas públicas e educação. Campinas, SP: Mercado das Letras, 2016.

ANDRADE, Cibele Yahn de. e cols. Acesso ao ensino superior no Brasil: equidade e desigualdade social. Revista de Ensino Superior Unicamp. Disponível em: https://www.revistaensinosuperior.gr.unicamp.br/artigos/acesso-ao-ensino-superior-no-brasilequidade-e-desigualdade-social. Acesso em: 10 out. 2012.

BRASIL. Constituição da República Federativa do Brasil de 1988. Diário Oficial da União, Brasília, DF: Senado, 5 out. 1988. Disponível em:

http://www.planalto.gov.br/ccivil_03/constituicao/constituicao.htm. Acesso em: 10 mar. 2017.

BRASIL. Economia e Emprego. Governo do Brasil. Censo 2010: cai taxa de analfabetismo no país. Brasília, 2011. Disponível em: http://www.brasil.gov.br/economia-eemprego/2011/11/censo-2010-cai-taxa-de-analfabetismo-no-pais. Acesso em: 10 maio 2018.

BRASIL. Emenda Constitucional n. 53, de 19 de dezembro. Dá nova redação aos art. $7^{\circ}, 23$, 30, 206, 208, 211 e 212 da Constituição Federal e ao art. 60 do Ato de Disposições Constitucionais. Diário Oficial da União, Brasília, 20 dez. 2006. Disponível em: http://www.planalto.gov.br/ccivil_03/constituicao/emendas/emc/emc53.htm. Acesso em: maio 2018.

BRASIL. Emenda Constitucional n. 59, de 11 de novembro de 2009. Acrescenta $\S 3^{\circ}$ ao art. 76 do Ato das Disposições Constitucionais Transitórias para reduzir [...], dá nova redação aos incisos I e VII do art. 208, [..], e dá nova redação ao $\S 4^{\circ}$ do art. 211 e ao $\S 3^{\circ}$ do art. 212 e ao caput do art. 214, com a inserção neste dispositivo de inciso VI. Diário Oficial da União, Brasília, 12 de nov. de 2009. Disponível em:

http://www.planalto.gov.br/ccivil_03/constituicao/emendas/emc/emc59.htm. Acesso em: 10 maio 2018.

BRASIL. Instituto Nacional de Estudos e Pesquisas Educacionais Anísio Teixeira. Sinopse Estatística da Educação Básica. Brasília, DF: Inep, 2010. Disponível em: http://download.inep.gov.br/informacoes_estatisticas/2010/sinopses_estatisticas_ed_basica/si nopse_educacao_basica_2010_03072017.zip. Acesso em: 10 maio 2018.

BRASIL. Instituto Nacional de Estudos e Pesquisas Educacionais Anísio Teixeira. Relatório do $2^{\circ}$ ciclo de monitoramento das metas do plano nacional de educação. Brasília, DF: Inep, 2018. Disponível em: http://portal.inep.gov.br/informacao-da-publicacao//asset_publisher/6JYIsGMAMkW1/document/id/6725829. Acesso em: 19 fev. 2020. 
BRASIL. Lei de Diretrizes e Bases da Educação Nacional n.9394/1996. Diário Oficial da União, Brasília, 23 dez. 1996. Disponível em: http://www.planalto.gov.br/ccivil_03/LEIS/19394.htm. Acesso em: 19 fev. 2020.

BRASIL. Ministério da Educação. Razões e princípios do plano de desenvolvimento da educação. Brasília, DF: MEC, 2012. Disponível em:

http://portal.mec.gov.br/arquivos/livro/livro.pdf. Acesso em: 10 maio 2018.

BRASIL. Plano Nacional de Educação 2001-2010 [recurso eletrônico]: Lei n. 010172, de 9 de janeiro de 2001. Brasília: Câmara dos Deputados, Edições Câmara. Disponível em: http://portal.mec.gov.br/arquivos/pdf/L10172.pdf. Acesso em: 10 maio 2018.

BRASIL. Plano Nacional de Educação 2014-2024 [recurso eletrônico]: Lei no ${ }^{\circ} 13.005$, de 25 de junho de 2014. Brasília: Câmara dos Deputados, Edições Câmara. Disponível em: http://www.observatoriodopne.org.br/uploads/reference/file/439/documento-referencia.pdf. Acesso em: 10 maio 2018.

DIAS SOBRINHO, José. Educação superior: bem público, equidade e democratização. In: Seminário tendências da educação superior no brasil, Sorocaba, SP. Sorocaba: Uniso; Ufscar, 2012.

DOURADO, Luís Fernando. Plano nacional de educação (2011-2020): avaliação e perspectivas. Goiânia: UFG; Belo Horizonte: Autêntica, 2011.

FRIGOTTO, Gaudêncio. A relação da educação profissional e tecnológica com a universalização da educação básica. Educ. Soc., Campinas, v. 28, n. 100, ed. esp., p. 11291152, out. 2007. Disponível em: http://www.scielo.br/pdf/es/v28n100/a2328100.pdf. Acesso em: 10 maio 2018.

INSTITUTO PAULO MONTENEGRO E AÇÃO EDUCATIVA. Evolução do alfabetismo funcional na última década, 2012. Disponível em: https://www.geledes.org.br/institutopaulo-montenegro-e-acao-educativa-mostram-evolucao-do-alfabetismo-funcional-na-ultimadecada/. Acesso em: 10 jan. 2013.

LIMA, Paulo Gomes. Ações afirmativas como eixo de inclusão de classes sociais menos favorecidas a universidade brasileira: um terceiro olhar entre pontos e contrapontos. Supervisor: José Luís Sanfelice. 2009. 178 f. Relatório final (pós-doutorado) - Universidade Estadual de Campinas, Faculdade de Educação, Campinas, SP. Disponível em: http://www.repositorio.unicamp.br/handle/REPOSIP/251449. Acesso em: 10 set. 2018.

LIMA, Paulo Gomes. Formação de professores: por uma ressignificação do trabalho pedagógico na escola. Dourados: Editora da UFGD, 2010.

LIMA, Paulo Gomes. Política e gestão da educação: recorrências da escola no Brasil. In: Congresso de Educação Básica (COEB), 2013, Santa Catarina. Anais[...]. Santa Catarina: Prefeitura Municipal de Florianópolis, 2013. Disponível em:

http://portal.pmf.sc.gov.br/arquivos/arquivos/pdf/14_02_2013_16.35.13.3cef8b55aa1e8bc771 652b70c75c1d20.pdf. Acesso em: 10 ago. 2018. 
MOÇO, Anderson. Balanço do Plano Nacional de Educação (PNE) 2001-2010. Nova Escola, 1 mar. 2010. Disponível em: https://novaescola.org.br/conteudo/2901/balanco-do-planonacional-de-educacao-pne-2001-2010. Acesso em: 10 out. 2018.

RAMOS, Elizabete. De que participação estamos falando? In: Graciano, Mariângela. (Coord.) O plano de desenvolvimento da educação. São Paulo: Ação Educativa, 2007. Disponível em: http://www.bdae.org.br/dspace/bitstream/123456789/2343/1/emquestao4.pdf. Acesso em: 10 jul. 2019.

SAMPAIO JR. Plínio de Arruda. Desenvolvimentismo e neodesenvolvimentismo: tragédia e farsa. Serv. Soc. Soc., São Paulo, n. 112, p. 672-688, out./dez. 2012. Disponível em: http://www.scielo.br/pdf/sssoc/n112/04.pdf. Acesso em: 10 out. 2018.

SAVIANI, Dermeval. PDE - Plano de Desenvolvimento da educação: análise crítica da política do MEC. São Paulo: Autores Associados, 2009.

TEIXEIRA, Elenaldo Celso. O papel das políticas públicas no desenvolvimento local e na transformação da realidade. Salvador, BA: Associação dos Advogados de Trabalhadores Rurais da Bahia, 2002. Disponível em:

http://www.dhnet.org.br/dados/cursos/aatr2/a_pdf/03_aatr_pp_papel.pdf. Acesso em: 10 jul. 2011.

TURRA, Clódia Maria Godoy; ENRICONE, Délcia; SANT’ANNA, Flávia Maria.

Planejamento de ensino e avaliação. Porto Alegre: Sagra, 1995.

\section{Como referenciar este artigo}

LIMA, Paulo Gomes. O planejamento da educação brasileira (PNE 2001-2010; 2014-2024). Revista Ibero-Americana de Estudos em Educação, Araraquara, v. 15, n. esp. 1, p. 704-718, maio 2020. e-ISSN: 1982-5587. DOI: https://doi.org/10.21723/riaee.v15iesp.1.13344

Submetido em: 30/10/2019

Revisões requeridas: 10/11/2019

Aprovado em: 20/12/2019

Publicado em: 30/04/2020 